\title{
Lingua Franca Intercultural Communication in Asia Pacific: Issues of Phonetic Competence, Phonological Transfer, and Perceptual Adaptation Strategies
}

\author{
Viktoriya Zavyalova $^{1} \&$ Oksana Primak ${ }^{1}$ \\ ${ }^{1}$ Oriental Institute-School of Regional and International Studies, Far Eastern Federal University, Vladivostok, \\ Russian Federation \\ Correspondence: Viktoriya Zavyalova, Oriental Institute-School of Regional and International Studies, Far \\ Eastern Federal University, Vladivostok, Russian Federation. E-mail: zavyalova.vl@dvfu.ru
}

Received: March 31, 2015 Accepted: July 13, 2015 Online Published: August 18, 2015

doi:10.5539/ass.v11n22p67 URL: http://dx.doi.org/10.5539/ass.v11n22p67

\begin{abstract}
The present study explores the challenges of lingua franca intercultural communication in Asia Pacific in view of non-native speakers' communicative (phonetic) competence in English. With the eastward shift of the global economy, and the advancement of English as the intermediary language in East Asia, strong demands in achieving high English proficiency have been imposed upon non-native interlocutors involved in lingua franca communication in the region. However, East Asian mesolect speakers of English tend to demonstrate particular features in their accent, which may somehow impede communication. The authors proceed from the assumption that accent in late bilingualism may be attributed to cognitive constraints mandatory for processing linguistically important phonological information of the speakers' native language, and, thus, should be viewed as a likely feature of non-native (L2) phonetic competence, i.e. phonetic organization of speech by functional language users. Phonetic competence, treated in the present article as part and parcel of overall human ability to communicate, is regarded especially important in the context of intercultural interaction via intermediary language. Given the intrinsic relation between the sound system of the language and mental structures (mapping of sound representations and meanings), as well as cognitive and mental computational processes characteristic of human speech, the role of phonetic means is argued to be vital for achieving real-life communicative goals, such as conveying a message, signaling interrupting, asking for clarification, changing the subject, concluding an argument, etc. The findings of the research on intelligibility of East Asian English accent, which involved a shadowing experiment with participation of non-native and native speakers of English, and of the survey on East Asian English comprehensibility, are presented. The importance of developing L2 phonetic competence and perceptual adaptation strategies in lingua franca intercultural communication is discussed.
\end{abstract}

Keywords: communicative/phonetic competence, English as Asian lingua franca, intercultural communication, non-native English accent, perceptual adaptation, shadowing experiment

\section{Introduction}

The imperative communication needs of the modern world demand searching for new approaches to studying the interaction of humans, their languages and cultures. As the process of globalization is promoting expansion of contacts between individuals and social groups from different countries, the emerging multilinguocultural international community gets balanced by the two opposite but parallel forces, namely: the move towards comprehensive integration (centripetal force), and the preservation of sovereignty and cultural identity (centrifugal force). The integration vector indicates the need to find universal tools of comprehensive interaction, which demands unification of communication, economic, political, and other standards. As a result, the world witnesses the active growth of new international political and economic associations that are served by the limited number of communication tools (languages of international communication), the changes of traditions and worldview in general, with tolerance, understanding of other languages and cultures being the key social principles nowadays. At the same time, people try to preserve their national identity, to maintain axiological foundations of their own culture, the viability of indigenous languages, and continuous transfer of ethno-cultural identity to future generations. 
The effect of these trends is clearly observed in the multiethnic Asia-Pacific region, which is the crossroads of languages, cultures, and civilizations of East and West. Therefore, the analysis of inter-language and intercultural contacts in the region is of particular relevance. It is worth noting that Russian Far East becomes a stable and robust integration platform for intercultural interaction of European and Asian countries in the Asia-Pacific region (Latushko \& Stavrov, 2014). This is due to a number of geopolitical and socio-economic factors, as the Russian Far East has common borders with such countries as China, Japan, the United States, and North Korea, which, in addition to direct contacts with Russia, get access to European and Central Asian markets via Russia. Being a direct participant of the integration processes, the Far East is actively involved in intercultural communication via English as an intermediary language, which has become a powerful communicative tool and a means of ethno-integration in this region (Proshina, 2001; Bolton, 2006; Honna, 2008). Common language of interethnic communication in the Asia-Pacific region, however, does not always guarantee mutual understanding and, hence, the success of communication. To achieve higher effectiveness in cross-cultural interaction between Russia and the countries of East and West it is vital to understand de facto linguistic variation caused by the cultural linguospecificity and identity of the English non-native mesolect ${ }^{1}$ speakers involved. The present article presents the results of the research on East Asian English accent perception by native English speakers in the Russian Far East lingua franca intercultural communication settings.

\section{Literature Review}

Our research objective demanded developing the theoretical framework for studying such problems as intercultural communication, communicative competence, linguistic competence and one of its key components-phonetic competence in both native and non-native languages, the phenomenon of non-native accent and its cognitive roots, efficient perception strategies in intercultural communication via intermediary language, and some other related issues. To theoretically evaluate the role of lingua franca phonetic competence in intercultural communication, firstly, we approached the issues of language and culture interdependence widely debated in modern linguistics, sociolinguistics, psycholinguistics, anthropology, and intercultural communication theory (Jenkins, 2000; Kabakchi, 1998; Kachru \& Nelson, 2001; Krysin, 2004; Oshchepkova, 1995; Passov, 2006; Safonova, 1996; Ter-Minasova, 2000). The concept of intercultural communication implies a combination of different forms of communication between individuals and social groups belonging to different cultures, while the very process of intercultural communication is structured depending on an array of psychological (internal) and situational (external) factors, namely gender and age of interlocutors, their profession, personal experience, social status, beliefs, as well as direct, indirect, mediated or immediate communication contexts, type of discourse, modalities, time context, etc. (Sadohin, 2007; Samosenkova, 2008).

However, all these factors depend directly upon the main condition-the overall level of communicative competence of the interlocutors. The Dictionary of Intercultural Communication Terms defines the term communicative competence as "the ability to use a language correctly and properly according to the rules and regulations in a society" (Zhukova et al., 2013, p. 178). The concept of communicative competence is closely related to the notion of linguistic competence since it can be interpreted as a combination of grammatical (covering all areas of linguistics), sociolinguistic (relating to etiquette and culture of speech), discursive (involving the use of cohesion and coherence to build oral and written statements), and strategic competencies that form the communication. According to Hymes (1972), communicative competence has several characteristic features, including: its dynamic nature (associated with changes in the level of knowledge and skills of interlocutors and their ability to communicate), implicitness (internal relationship between cognitive and non-cognitive components of communication, such as motivation, attitudes), and complexity (assuming a set of linguistic, psychological and sociological factors).

In the Russian linguistic school, Vyatyutnev (1974) defines speech production and perception processes as basic necessities, leading to success of communication. Safonova (1996) distinguishes linguistic, oral and socio-cultural components of communicative competence, while Zimnyaya (1989) adds phonological, lexical, grammatical, and geographic components. In this research, we proceed from the assumption that communicative competence is a symbiosis of two basic competencies, namely: intercultural communicative-pragmatic (including discursive, strategic, and socio-ethno-cultural, psychological, and other extralinguistic components) and linguistic.

Our personal experience and research data lead us to assume that both intercultural communicative-pragmatic and linguistic competences in a foreign language rest upon a more specific phonetic competence, as it is phonetic organization of speech that basically determines the success or failure of verbal interaction in the context of intercultural communication. Khomutova (2013) gives a detailed description of the structure and content of phonetic competence, while the principles of a foreign-language phonetic-phonological competence are 
developed by Goncharova (2006). Following these researchers, we believe that the formation of phonetic-phonological skills traditionally underlies learning a foreign language: auditory-pronunciation skills help correlate the sound with the meaning, i.e. ensure mapping of sound representations and meanings, as well as cognitive and mental computational processes characteristic of human speech. Moreover, the language phonetic means often compensate the lack of lexical - grammatical context. Indeed, the efficient formation of phonetic-phonological skills is the foundation of a successful oral expression, as the basic language proficiency includes the development of these skills in all kinds of speech activity, their interrelationship and interdependence. Hence, phonetic competence is vital for achieving real-life communicative goals such as conveying a message, signaling interrupting, asking for clarification, changing the subject, concluding an argument, etc. Functional diversity of phonetic competence in a foreign language allows identifying such components as sociolinguistic, social, socio-cultural, discursive, strategic, and many others. Thus, oral phonation in native or foreign language can be treated as an informative carrier of both the general message, and cultural norms of speech etiquette, and models of oral behavior. The ethno-cultural originality of English varieties in the world that was first described in Kachru's theory of three circles (the inner circle, the outer or extended circle, and the expanding circle), has demanded the formation and rapid development of the new scientific paradigm of the world varieties of English-World Englishes (Kachru \& Nelson, 2001; Proshina, 2001).

In English as a lingua franca communication, as well as in intercultural communication via other languages, the listener must understand the statement and communicative intention of the speaker, and, adequately using his/her communicative, pragmatic, and linguistic skills in verbal/non-verbal form, respond to the message received. To accomplish these tasks, the participants of intercultural communication in English should develop auditory and pronunciation skills of monologue and dialogue, as well as the skills of phonetic culture in a foreign language in order to achieve greater authenticity, and hence comprehensibility. Passov (2006) concludes that pronunciation skills in speech are very important communicative characteristics, and their changes (or excessive phonetic variation) may impede the process of communication. On the one hand, distinctive acoustic parameters define general norms of speech, on the other-phonetic units complement each other and, if remote from the context, can lose their meaning. Therefore, direct sound realization in real speech sequence, built in conformity to all factors of a particular communicative situation and to the type of a communicative context, plays a significant role in adequate verbal communication and interpretation of communicative intentions by the interlocutors.

The de facto contexts of intercultural communication via English as a lingua franca in the Asia-Pacific region reveal that East Asian speakers of English quite often demonstrate mesolect phonetic competence, which sometimes can be not sufficient for successful interpretation of communicative message by the listeners. Mesolect phonetic competence implies a set of phonetic features which specify a particular phonetic variation that can be interpreted as fairly accented speech likely to affect intelligibility. In this study we proceed from the assumption that accent is a feature occurring in late bilingualism. It may be attributed to cognitive constraints that have formerly developed as mandatory for processing linguistically important phonological information of the speakers' native language (L1), and, thus, should be viewed as an expected feature of their non-native phonetic competence in a foreign language (L2). The above-mentioned cognitive pressure of the mother tongue is widely known as the phenomenon of phonological transfer, which is, as many linguists claim, quite often ascribed to the differences in the phonetic systems of the languages in contact (Juffs, 1990; Flege et al., 1997; Brown, 2000). Phonological transfer is traditionally defined as an influence of L1 phonology upon that of L2, manifesting itself in non-native speakers' retaining a foreign accent in both L2 speech perception and production, and is considered to be the tightest area of interference since, although many adult learners are able to eventually acquire a native-like grammatical accuracy in a foreign language (L2), their L2 speech will most probably be characterized by non-native deviations in phonology. Awareness of L1 influence on L2 learning gave rise to Lado's Contrastive Analysis Hypothesis according to which the more similar the sound systems of the two languages in contact are, the easier it is for the learner to grasp L2 phonological organization, whereas differences in phonological units will pose major difficulty (negative transfer) (Lado, 1957). The contrastive analysis which suggests writing formal descriptions of the two languages, picking up similarities and differences, and making predictions of difficulty through contrasts, has been the fundamental method of studying the phonological transfer in structural linguistics. With the rise of cognitive linguistics which is seeking the relationship between human language, the mind and socio-physical (embodied) experience, the new approaches to language study have developed (Evans, 2012). The guiding principle behind cognitive linguistics in general is that "the human language ability is not separate from the rest of cognition, that the storage and retrieval of linguistic data is not significantly different from the storage and retrieval of other knowledge, and that use of language in understanding employs similar cognitive abilities to those used in other non-linguistic tasks" (Mompeán-González, 2006, p. vii). Cognitive study of phonological transfer is inherently linked to the study of 
bilingualism as it is cognition of a bilingual individual that matters. The new cognitive approaches to the problem are characterized by the convergence of the disciplines that contribute to it, including psychology, linguistics, applied linguistics and second language acquisition, and neuroscience.

Comparing the two paradigms - structural and cognitive-linguists sometimes negate the validity of the former. In relation to phonological transfer there is an opinion that "...the prevailing metaphor of transfer of skills is misleading, and that what happens is access to an already existing general cognitive skill" (Walter, 2008, p. 245). We suggest that there is no conflict between the two approaches of studying the problem. On the contrary, cognitive approach to phonological transfer has been a consistent development of the earlier research instruments: having realized constraints of studying language transfer within contrastive analysis framework, linguists have approached this phenomenon at a cognitive perspective. The cognitive paradigm in L2 phonological transfer research implies understanding individual cognitive abilities of a bilingual, the difference between perception and production mechanisms at the phonological level and the role of phonology in the process of L2 acquisition, with phonological memory (loop) being considered a crucial cognitive instrument.

Although it is a well-accepted fact that phonology studies have always been the flagship in linguistics, phonological work in cognitive linguistics, strange as it may seem, has been "sparse in comparison with the attention paid to other areas of study like semantics or grammar" (Walter, 2008, p. 245). Cognitive phonology treats pronunciation and identification of phonological contrasts as cognitive skills that are related to neurophysiological processes which happen in the human's brain/mind (Lakoff, 1993; Hale \& Reiss, 2000; Hulst, 2003; Fraser, 2006; Mompeán-González, 2006; Nathan, 2008; Burton-Roberts, 2011, etc.). Not many researchers in Russia have addressed the issue of phonological transfer from a cognitive perspective so far, so the present article is a small contribution into the problem of phonological transfer and L2 accent variation from the cognitive phonology perspective.

Accent variation in non-native speech requires particular perceptual adaptation on the part of the listener. Perceptual adaptation involves learning a set of non-linguistic speech characteristics that must be discarded so that the linguistic meaning can be uncovered. The previous research on developing perceptual adaptation strategies (Clerke \& Garett, 2004; Bradlow \& Bent, 2008) provides controversial evidence on rapidness with which listeners can get adjusted to accented speech. However, two factors can be identified as supposed to be guiding when conducting experiments on perception of foreign-accented speech, namely: 1) differentiation between less and more experienced listeners, and 2) listener's familiarity with a particular accent. To experimentally prove the importance of lingua franca phonetic competence in intercultural communication we applied a variation of shadowing technique, in which subjects repeat speech immediately after hearing it. This experimental technique was introduced by Chistovich (1960) and is still used in modern research on speech perception and production (see Nye \& Fowler, 2003).

\section{Method}

\subsection{Participants}

\subsubsection{Audio Stimuli Collection}

Asian-English late bilinguals ${ }^{2}$ ( $\mathrm{n}=40$, including 22 male and 18 female native speakers of Chinese, Korean, and Japanese, aged 20-35, students) were recorded as they performed a reading task.

\subsubsection{Speech Shadowing Experiment}

Native listeners of English ( $\mathrm{n}=6$, including 3 Americans, 3 Australians, aged 25-55) participated in the accented speech listening comprehension and reproduction experiment.

\subsection{Materials and Recording}

The recordings were made in a sound-proof booth with the help of professional audio recording equipment. The total duration of experimental material is $\sim 40$ minutes (audio stimuli $\sim 20 \mathrm{~min}$; shadowed speech samples 20 $\min )$.

\subsection{Procedure}

The experiment on comprehensibility of Asian Englishes (perception by native speakers) was designed to be conducted in several stages. First, the collection of the recorded reading samples (accented speech stimuli) was made by the researchers, as the Asian-English bilinguals were reading aloud three short specially selected English texts. At the next stage, in the sound-proof booth, native listeners of English were instructed to listen to the above described audio stimuli in the earphones, and to reproduce the speech chunks they heard immediately, in the pauses provided, in their natural speech manner (speech shadowing task). No information of the audio 
stimuli was given to the listeners in advance. The elicited shadowed speech samples produced by the native English speakers were audio-recorded. The next stage included conducting comparative analysis of the audio stimuli and shadowed speech samples with the purpose to identify the cases of misinterpretation. The last stage held upon performing the shadowing task, involved conducting a survey, in which the native speakers were asked to fill in a specially constructed questionnaire on accented speech comprehensibility.

\section{Results and Discussion}

The processing of the audio stimuli and elicited shadowed speech samples included auditory analysis, making transcripts, and providing $\mathrm{IPhA}^{3}$ transcription of speech chunks that were mispronounced by the Asian-English bilinguals and, therefore, misinterpreted by the native speakers of English (Note: if listeners completely failed to understand the stimuli they would say phrases like: I don't understand/Nothing/Something about..., etc.). The original English text (OT), the transcription of the accented stimuli (TAS) and the transcript of the shadowed speech (TSS) were compared as parallel texts. Below are several examples:

1) OT: You couldn't have called her beautiful.

TAS: [ju: (pause) 'ka: 'hæ: 'bjut'fos] (NNS $\left.{ }^{4}-K o r e a n-m 1\right)$

TSS: You can't have built for ( $\mathrm{NS}^{5}$-Australian-m1)

2) OT: If you took her to pieces...

TAS: [If 'ju: 'to:k 'hæ: 'to: 'pæ: 'sis] (NNS-Japanese-f3)

TSS: Something about taking her places... (NS-American-m2)

3) OT: She was ... amazingly well-read

TAS: ['fi: 'wa:(s) 'æ: 'nI'mI'zi'lı 'we'dra] (NNS-Chinese-m5)

TSS: Something about animals...(NS-American-m2)

4) OT: Her parties were a mixture of ...

TAS: ['hз: 'pa: 'ti:s 'wa: ə 'mikəsət」ərə] (NNS-Chinese-f4)

TSS: Her practice was a mixture of...(NS-American-f3)

5) OT: When is your boarding time?

TAS: ['we(n): 'i:s 'ju: 'pu: 'ti:n 'ta:] (NNS-Korean-f4)

TSS: Where is your Putin tar (NS-American-f3)

The analysis of the comprehension breakdowns allowed to identify those phonetic segments and prosodic complexes, mispronunciation of which was likely to cause problems in Asian English speech signal decoding by the native speakers of English and, hence, might lead to misunderstanding. At the segmental phonetic level the most part of incorrect interpretations was caused by insufficient phonetic contrasts as listed below:

1) Acoustic discrimination of voiced and voiceless consonants: e.g. $p / b, k / g, t / d, s / z, f / v$, etc.,

2) Acoustic discrimination of short and long vowels: e.g. $A / a$ :, $t / i$;,$U / u$;, etc.,

3) Acoustic discrimination of monophthongs (both short and long) and diphthongs: e.g. $\Lambda$ - $a: / a U, b-J: / J$, $b-\supset: / \partial U$, I-i i:/ro, e-ce/ez, $v-u: / v$, etc.

The lack (or insufficiency) of the above mentioned contrasts in the English speech by mesolect Asian-English bilinguals can be attributed to the absence of similar oppositions in the phonetic systems of their native languages, which function as "phonological sieves" (in Polivanov's terms) in acquiring and speaking the foreign language in late bilingualism. To effectively comprehend the accented English speech characterized by the above described features, the interlocutor acting as a listener in lingua franca intercultural communication situations in Asia Pacific needs to develop perceptual adaptation skills, i.e. a set of cognitive operations allowing to quickly and adequately restore the original linguistic meaning, in order to get the communicative intention of the speaker.

The results of the objective analysis of misinterpretation cases in speech were supported by the data received from questionnaires on accented speech comprehensibility filled in by the participants of the shadowing experiment. The questionnaire included introductory questions related to specifying the native language of the listener, and other languages he/she had command of. Answering the information-seeking questions in the main body of the questionnaire, native listeners were supposed to: 
1) Rate the accent of each speaker on the scales with the following parameters: heavy/mild accent; not accented; other impression;

2) Identify each speaker's country of origin;

3) Rate the intelligibility of each speaker's accent on the scale from 1 to 7 , with 1 being least intelligible, and 7-most intelligible;

4) (if had difficulties with perceiving the accent) Indicate the factors, which affected comprehension, each on the scale from 1 to 7 :

(a) pronunciation of particular sounds, (b) restructuring of syllables, (c) shifting word stress, (d) modification of rhythm in the whole phrase, (e) modification of melodic contours, $(f)$ modification of tempo, ( $g$ ) inadequate placement of pauses, $h$ ) other factors.

The concluding part of the questionnaire was designed to elicit responses on the listener's general ability to distinguish between European and Asian accents; decide upon which accents (European or Asian) are more comprehensible; describe the most salient features of the Asian accent; and name the perception strategies the listener applies when listening to heavily accented speech.

The quantitative data of the survey allowed identifying those phonetic factors that, in the opinion of the native English listeners, adversely affected the speed, accuracy, and correctness of their perceiving the accented Asian English speech. According to the subjective assessment by the listeners in the shadowing experiment, all negative factors can be distributed the following way: distortions at the level of (a) individual speech sounds (20\%), (b) syllabic structure (15\%), (c) accentual and (d) rhythmic structure (15\% and $20 \%$, respectively), and (e) melodic contour of the phrases (15\%). Perception failures due to ( $\mathrm{f}$ ) incorrect localization and redundancy of the intra-and intersyntagmatic breaks are estimated at $10 \%$. It must be noted that $(\mathrm{g})$ slower tempo of Asian-English speech is not widely reported as playing a significant role in perception $(2 \%)$, while $(\mathrm{h})$ additional comprehension impeding factors (3\%) are specified as follows: pronunciation of personal names, limited context, and the lack of visual cues. Not all native listeners accurately determined the nationality of each speaker; however, the type of accent in all the audio stimuli was almost unmistakably identified as Asian (90\%). Responding to the concluding set of questions in the questionnaire all native listeners $(100 \%)$ noted the possibility of perceptual discrimination between European and Asian types of accent, and recognized European accent type as a clearer (90\%) one, with $10 \%$ of the respondents emphasizing the need to take into account the individual characteristics of the speaker, the variability within two accentual types, and the preceding accent perception experience. Among the most salient features of Asian-type accent in English speech the following are mentioned: (1) non- or underdifferentiation of segmental phonological contrasts between the /r/-/l/ and /æa/-/e/, (2) substitution of specific sounds, reduction or distortion of the final sounds or even final syllables in words ("cutting off the ends of words"; "ending the missing syllables or miss-pronounced"), (3) excessive length and nasalization of vowels, (4) lack of word and phrasal stress and, conversely, (5) excessive accentuation, (6) intonation contour distortion, (7) lack of phonetic connectedness ("linking"), and (8) acoustic "weakness", i.e. the absence of proper acoustic contrasts in speech ("weak sound"). Among the individual strategies of the accented speech perception (or comprehension repair strategies), the informants mention the following: it is useful to recognize and be aware of the most common accentual features characteristic of the English non-native speech; if possible, listeners should apply to such strategies as asking for repetition and forecasting (predicting and building up the content out of the preceding context); it is vital to focus on the context; listen attentively to the reliable segments (recognizable syllables); guess the meaning of some words; restate what has been heard to validate proper understanding of messages; compare/contrast the speaker's speech with the speech of familiar speakers of the same language, etc. Unanimously, the native listeners point out that auditory perception of the accented speech might get increasingly easier in case eye contact with the speaker is established, which indicates the need for multimodal interfaces in communication.

\section{Conclusion}

The significance of studying phonetic and phonological aspects of language variation in intercultural communication via the intermediary language is determined by the psycho-physiological and neuro-linguistic factors: on the one hand, interpretation of the phonetic information occurs at the initial stage of speech perception, providing a transition from speech signal to a sequence of speech units of various levels and their understanding, and, on the other hand, generation of speech in the form of acoustic continuum represents the final stage of forming a voice message. In other words, phonetic and phonological encoding/decoding of information is the basis of psycho-physiological and neurological processes of speech activity as a whole. While acquiring and operating a foreign-language sound code necessary for intercultural communication, late bilinguals experience strong interference of their native tongues at all linguistic levels, with the phonetic one being "the last stronghold that 
falls". It used to be taken for granted that accent in late bilingualism was unlikely to be reduced to minimum. However, in terms of modern concepts of bilingualism the development of phonetic competence up to the acrolect level in a foreign language, is considered possible because the processes of learning a native and a foreign languages exhibit more similarities than differences, and because the mechanisms of speech activity in the native and foreign languages are admitted to be the same (Zimnyaya, 1989).

For the development of lingua franca phonetic competence as a component of communicative competence in intercultural communication, the following steps seem necessary to be taken:

1) In order to develop linguistic competence, a person should study and implement a consistent comparison of phonetic-articulatory bases of two languages (native and foreign), the work of the organs of speech, the principles of voice, and intonation contour types.

2) As part of sociolinguistic competence, we should consider the phenomena influencing the choice of phonetic forms, depending on the age of the interlocutor, his/her status, and level of education, as well as the ability to apply this knowledge in real-life communication context to achieve mutual understanding.

3) In the discursive competence, attention should be focused on improving the phonetic components such as prosody and intonation (melody, phrasal stress, rhythm, tempo, and pausation).

4) The enhancement of strategic competence should include phonetic knowledge, aimed at developing various lexical and grammatical structures.

5) The phonetic aspect of social competence requires enhancing the ability to understand and produce the statement in accordance with the purpose and conditions of communication.

6) With regard to social cultural competence, literary norms of pronunciation, the phonetic system of the native and the target language, their similarities and differences need to be raised awareness of.

Thus, we assume that a language can serve as a lingua franca tool of intercultural communication only under the condition that it is realized in the form of comprehensible spoken and perceived sounds. Being the basic characteristics of speech, phonetic features are the key ones for the development and improvement of overall communication skills in a lingua franca in the context of globalization and closer interaction between people with diverse linguistic and cultural backgrounds. The persistent formation of L2 communicative competence in general and phonetic competence in particular, is a pre-requisite necessary for achieving communicative goals in lingua franca intercultural communication settings. At the same time, the phenomenon of language variability needs to be viewed as an inherent and de facto part of the lingua franca intercultural communication. Hence, it is crucial to take the lingua franca accent variation characteristics into consideration in order to develop perceptual adaptation strategies on the part of the interlocutor acting as a listener. The cognitive ability to distinguish between non-linguistic speech characteristics and the linguistic meaning should be formed as one of the primary communication skills in English as a lingua franca intercultural communication in Asia Pacific. We strongly believe that adequate assessment and consideration of such issues as L2 phonetic competence, phonological transfer, and perceptual adaptation strategies in lingua franca intercultural communication can help to avoid many flaws in a foreign language teaching and international contacts practice as it allows to find ways of improving the effectiveness of communication strategies in order to achieve mutual understanding in intercultural communication.

\section{Acknowledgments}

This work was supported by the Far Eastern Federal University, project \# 14-08-05-14_и.

\section{References}

Bolton, K. (2006). World Englishes Today. In B. B. Kachru, Y. Kachru, \& C. L. Nelson (Eds.), The Handbook of World Englishes (pp. 240-269). Oxford: Blackwell Publishing. http://dx.doi.org/10.1002/9780470 757598.ch15

Bradlow, A., \& Bent, T. (2008). Perceptual adaptation to non-native speech. Cognition, 106(2), 707-729. http://dx.doi.org/10.1016/j.cognition.2007.04.005

Brown, C. (2000). The interrelation between speech perception and phonological acquisition from infant to adult. In J. Archibald (Ed.), Second Language Acquisition and Linguistic Theory (pp. 4-63). Oxford: Blackwell.

Burton-Roberts, N. (2011). On the grounding of syntax and the role of phonology in human cognition. Lingua, 121(14), 2089-2102. http://dx.doi.org/10.1016/j.lingua.2011.08.001

Chistovich, L. (1960). Classification of rapidly repeated speech sounds. Akusticheskii Zhurnal, 6, 392-398. Trans. 
in Soviet Physics-Acoustics, 6, 393-398. New York: American Institute of Physics.

Clarke, C., \& Garrett, M. (2004). Rapid adaptation to foreign-accented English. Journal of the Acoustical Society of America, 116(6), 3647-3658. http://dx.doi.org/10.1121/1.1815131

Evans, V. (2012). Cognitive linguistics. WIREs Cogn. Sci., 3. http://dx.doi.org/10.1002/wcs.1163

Flege, J., Frieda, E., \& Nozawa, T. (1997). Amount of native language use affects the pronunciation of an L2. Journal of Phonetics, 25(2), 169-186. http://dx.doi.org/10.1006/jpho.1996.0040

Fraser, H. (2000). Helping teachers help students with pronunciation: A cognitive approach. Prospect, 21(1), $80-96$.

Goncharova, N. (2006). Formirovanie inoyazychnoy fonetiko-fonologicheskoy kompetentsii u studentov-lingvistov (na materiale angliyskogo yazyka): Avtoref. diss. ... kand.ped nauk [Formation of a foreign language phonetic-phonological competence in students-linguists (on the English language material): Autoref. of dissert. ... Cand.Ped.Sciences]. Stavropol': Izd-vo Stavrop. universiteta.

Hale, M., \& Reiss, Ch. (2000). Phonology as cognition. In N. Burton-Roberts et al. (Eds.), Phonological Knowledge (pp. 161-184). Oxford: Oxford University Press.

Honna, N. (2008). English as a multicultural language in Asian contexts: Issues and Ideas. Tokyo: Kurosio Publishers.

Hulst, H. van der. (2003). Cognitive Phonology. Germania at alia. A linguistic webschrift for Hans den Besten on the occasion of his 55th birthday, 1-24.

Hymes, D. (1972). On Communicative Competence. In J. B. Pride, \& J. Holmes (Eds.), Sociolinguistics (pp. 269-293). Harmondsworth: Penguin.

Jenkins, J. (2000). The Phonology of English as an International language. Oxford: Oxford University Press.

Juffs, A. (1990). Tone, Syllable Structure and Interlanguage Phonology: Chinese Learners' Stress Errors. International Review of Applied Linguistics, 28, 99-117. http://dx.doi.org/10.1515/iral.1990.28.2.99

Kabakchi, V. (1998). Osnovy angloyazychnoy mezhkul'turnoy kommunikatsii [Basics of English Intercultural Communication]. SPb: Izd-vo RGPU im. A.I. Gertsena.

Kachru, B., \& Nelson, C. (2001). World Englishes. In A. Burns, \& C. Coffin (Eds.), Analyzing English in a Global Context (pp. 9-25). London: Routledge.

Khomutova, A. (2013). Foneticheskaya kompetentsiya: struktura, soderzhanie [Phonetic competence: structure, content]. Vestnik Yuzhno-Ural'skogo gosudarstvennogo universiteta. Seriya: Lingvistika, 2(10), 71-76. Yuzhno-Uralsk: Izd-vo Yuzhno-Ural'skogo gosudarstvennogo universiteta.

Krysin, L. (2004). Russkoe slovo, svoe $i$ chuzhoe: Issledovaniya po sovremennomu russkomu yazyku $i$ sotsiolingvistike [Russian word, native and foreign. Studies on modern Russian and sociolinguistics]. M.: Yazyki slavyanskoy kul'tury.

Lado, R. (1957). Linguistics Across Cultures. Ann Arbor: University of Michigan Press.

Lakoff, G. (1993). Cognitive Phonology. In Goldsmith-John (Ed.), The Last Phonological Rule: Reflections on Constraints and Derivation (pp. 117-145). Chicago: University of Chicago.

Latushko, Yu., \& Stavrov, I. (Eds.). (2014). Mezhkul'turnaya kommunikatsiya v Aziatsko-Tihookeanskom regione: istoriya i sovremennost': XIV vseross. nauch. konf. molodyh uchenyh (s mezhdunarodnym uchastiem), 12-14 maya 2014 g.: materialy konferentsii. [Intercultural communication in Asia-Pacific Region: history and present state: XIV All-Russ. Scient. Confer. of Young Scientists (with international participation), Proceedings, May 12-14, 2014]. Vladivostok: IIAE DVO RAN.

Mompeán-González, J. A. (2006). Introduction: cognitive phonology in cognitive linguistics. International Journal of English Studies, Monograph: Cognitive Phonology, 6(2), vii-xii.

Nathan, G. (2008). Phonology: A Cognitive Grammar Introduction. Amsterdam: John Benjamins. http://dx.doi. org/10.1075/clip.3

Nye, P., \& Fowler, C. (2003). Shadowing latency and imitation: the effect of familiarity with the phonetic patterning of English. Journal of Phonetics, 31, 63-79. http://dx.doi.org/10.1016/S0095-4470(02)00072-4

Oshchepkova, V. (1995). Kul'turologicheskie, etnograficheskie i tipologicheskie aspekty lingvostranovedeniya: avtoref. dis. ... d-ra filol. nauk [Culturological, ethnographical and typological aspects of language and 
culture studies: autoref. of dissert. ... of Doctor.Philol.Sciences]. M.: Mosk. ped. in-t.

Passov, E. (2006). Sorok let spustya ili sto i odna metodicheskaya ideya [Forty years later or one hundred and one methodological ideas]. M.: Glossa-Press.

Proshina, Z. (2001). Anglijskij jazyk i kul'tura narodov Vostochnoj Azii [The English language and the culture of the East Asian people]. Vladivostok: Izdatel'stvo Dal'nevostochnogo universiteta.

Sadohin, A. (2007). Kul'turologiya: teoriya i istoriya kul'tury: Uchebnoe posobie [Culture Studies: theory and history of culture: training manual]. M.: Eksmo.

Safonova, V. (1996). Izuchenie yazykov mezhdunarodnogo obshheniya v kontekste dialoga kul'tur i tsivilizatsiy [Study of languages of international communication in the context of dialogue between cultures and civilizations]. Voronezh: Istoki.

Samosenkova, T. (2008). Kul'tura professional'nogo obshheniya v sisteme podgotovki spetsialistov-filologov dlya zarubezhnyh stran: Monografiya [Culture of professional interaction in the system of training specialists-philologists for foreign countries: Monograph]. Belgorod: IPC (POLITERRA).

Ter-Minasova, S. (2000). Yazyk i mezhkul'turnaya kommunikatsiya: ucheb. posobie [Language and intercultural communication: training manual]. M.: Slovo/Slovo.

Vyatyutnev, M. (1984). Teoriya uchebnika russkogo yazyka kak inostrannogo [Theory of textbook of Russian as a foreign language]. M.: Russkiy yazyk.

Walter, C. (2008). Phonology in Second Language Reading: Not an Optional Extra. Tesol Quarterly, 42(3), 455-474.

Zhukova, I., Lebed'ko, M., Proshina, Z., \& Yuzefovich, N. (2013). Slovar' terminov mezhkul'turnoy kommunikatsii [Dictionary of Intercultural Communication Terms]. M.: Flinta.

Zimnyaya, I. (1989). Psihologiya obucheniya nerodnomu yazyku [Psychology of teaching a foreign language]. M.: Russkiy yazyk.

\section{Notes}

Note 1. Sociolinguistic terms basilect, mesolect, and acrolect are used in this article to differentiate between three levels of linguistic competence (elementary, intermediate, and advanced, correspondingly).

Note 2. In this article we analyze accented speech of late bilinguals, i.e. late learners of a second/foreign language.

Note 3. IPhA-International Phonetic Alphabet.

Note 4. NNS-Non-Native Speakers of English (functional users).

Note 5. NS-Native Speakers of English.

\section{Copyrights}

Copyright for this article is retained by the author(s), with first publication rights granted to the journal.

This is an open-access article distributed under the terms and conditions of the Creative Commons Attribution license (http://creativecommons.org/licenses/by/3.0/). 